\title{
Comparison of Vietnamese and Japanese Rice Cultivars in Terms of Physicochemical Properties
}

\author{
Uyen Thi Tran, ${ }^{1}$ Hiroshi OKadome, ${ }^{2}$ Masatsune Murata, ${ }^{1}$ Seiichi Homma ${ }^{1}$ and Ken'ichi OHTSUbO ${ }^{1,2^{*}}$ \\ ${ }^{1}$ Graduate School of Life Sciences and Humanities Ochanomizu University, 2-1-1 Otsuka, Bunkyo, Tokyo, 112-8610, Japan \\ ${ }^{2}$ National Food Research Institute 2-1-12 Kannondai, Tsukuba, Ibaraki, 305-8642, Japan
}

Received May 31, 2001; Accepted September 26, 2001

\begin{abstract}
A total of 20 Vietnamese and Japanese rice varieties were evaluated for their main chemical components, physical properties, cooking quality, pasting properties, amylase activity, and instrumental measurements. Based on these quality evaluations, it was concluded that Vietnamese rice varieties are of the indica type which are characterized by having intermediate or high amylose content, high protein content and fat acidity, high water uptake ratio, expanded volume, and a cooked form texture which is high in hardness, low in stickiness, and has very low balance degree. Both Vietnamese and Japanese glutinous rice have similar characteristics of very high whiteness, low amylose content, low peak viscosity, and high stickiness. Japanese milled rice glossiness was greater than that of Vietnamese milled rice. In addition, Vietnamese rice had a lower "Mido" score than Japanese rice. In an instrumental test using a "Taste Analyzer," both Vietnamese and Japanese rice gave a significantly high correlation with the chemical components in moisture and protein content measurements.
\end{abstract}

Keywords: physicochemical, cooking quality, pasting properties, amylase activity, instrumental test

Rice (Oryza sativa L.) is one of the leading crops of the world in addition to wheat and maize. Rice also is the principal food cereal in tropical Asia, where $90 \%$ of the world's rice crop is grown and consumed. Vietnam with a population composed nearly $80 \%$ of farmers, considers rice as a major plant, a stable food and a strategic export item. Along with the improvement of the economic situation, rice production in Vietnam has developed rapidly. According to the Vietnamese Statistical Publishing House, rice export output in 1999 was more than double that of 1995 and is increasing rapidly, the value, however, has not enhanced correspondingly. During the past years, because of the emergency to solve the "eating problem," Vietnam has paid more attention to the development of short-term-maturation and high yielding rice varieties. This has resulted in a surplus of the output, but the value of rice, both in the domestic and world markets, has not risen correspondingly. Recently it has seemed that "the age of quality rather than quantity" has dominated. Increasing demand for high quality rice varieties by Vietnamese people and Vietnamese rice exporters is becoming a noticeable trend which is prompting plant breeders to develop new and improved varieties; these require a full quality evaluation for screening and classification.

According to Ohtsubo et al. (1993), grain quality evaluation is intended to select high quality rice easily and accurately, and to characterize the processing suitability of the newly bred high quality varieties. Quality evaluation of rice in Japan is carried out by the application of a sensory test and physicochemical measurements. The former is a basic method although it requires a large amount of samples and many panelists. The latter is an

*To whom correspondence should be addressed.

E-mail: kenohtsu@nfri.affrc.go.jp indirect method to estimate the eating quality based on the chemical components, cooking quality, pasting properties, and the physical properties of cooked rice.

Here, we would like to present the physicochemical evaluation of some Vietnamese and Japanese rice cultivars using traditional and novel techniques recently applied in Japan.

\section{Materials and Methods}

Rice samples and preparation Fifteen Vietnamese rice cultivars including glutinous, non-glutinous, and aromatic local lines and 5 selected Japanese rice varieties, including glutinous, low amylose, ordinary and high amylose were used for physicochemical, cooking quality, pasting properties, amylase activity, and instrumental experiments (Table 1). Sample preparation in brief was as follows: harvested in 1999, the samples were stored at low temperature $\left(4^{\circ} \mathrm{C}\right)$ before the test. They were milled using a Yamamoto polisher (Rice Pal 31, Tendo), to an extent of $10 \%$ (degree of polish) or $90 \%$ milling yield. Milled rice was powdered using a Cyclone sample mill from UDY Corp., Ft. Collins, CO.

Main chemical components Moisture content of milled rice grain was measured by oven-dry method, drying the flour for $1 \mathrm{~h}$ at $135^{\circ} \mathrm{C}$. Amylose content of the milled rice was estimated by the iodine colorimetric method of Juliano (Juliano, 1971). A calibration chart used to determine the amylose content of the rice samples was obtained by precisely weighing standard amylose (Potato amylose type III, Sigma Co., St. Louis, MS) and amylopectin (Waxy rice amylopectin, Shimada Co., Japan) based on dry matter. The nitrogen content of milled rice was determined by the Kjeldahl method. The protein content of milled rice was obtained from nitrogen by multiplying it by a factor 5.95. Fat acidity was determined by the spectrophotometric method of 
Table 1. The rice varieties collected for research.

\begin{tabular}{clll}
\hline Number & \multicolumn{1}{c}{ Name } & Country & \multicolumn{1}{c}{ Note } \\
\hline 1 & P4 & Vietnam & Non-glutinous variety \\
2 & Tam Ap Be & Vietnam & Aromatic, local rice variety \\
3 & Bac Huong & Vietnam & Local variety \\
4 & Tam Xoan & Vietnam & Aromatic, local variety \\
5 & Nep Cai Hoa Vang & Vietnam & Glutinous, local variety \\
6 & Nep Thuy Tien & Vietnam & Glutinous, local variety \\
7 & IR64 & Vietnam & Non-glutinous variety \\
8 & Ai32 & Vietnam & Non-glutinous variety \\
9 & X21 & Vietnam & Non-glutinous variety \\
10 & Q5 & Vietnam & Non-glutinous variety \\
11 & C70 & Vietnam & Non-glutinous variety \\
12 & Khang Dan & Vietnam & Non-glutinous variety \\
13 & XI23 & Vietnam & Non-glutinous variety \\
14 & 108AV & Vietnam & Non-glutinous variety \\
15 & IR352 & Vietnam & Glutinous variety \\
16 & Koshihikari & Japan & Non-glutinous variety \\
17 & Hiyokumochi & Japan & Glutinous variety \\
18 & Hoshinishiki & Japan & High amylose variety \\
19 & Nipponbare & Japan & Non-glutinous variety \\
20 & Milkyqueen & Japan & Low amylose variety \\
\hline
\end{tabular}

Ohtsubo (Ohtsubo et al., 1987), a modification of the Duncombe method (Duncombe, 1963). A calibration chart was obtained using $0-1.1 \mathrm{mM}$ standard linoleic acid in toluene. A regression equation was prepared for estimating fatty acid content in the unknown samples. Fat acidity was expressed as $\mathrm{mg}$ potassium hydroxide $(\mathrm{KOH})$ required to neutralize free fatty acid contained within $100 \mathrm{~g}$ of rice flour (based on dry matter). All analyses were conducted in duplicate on each sample and the results calculated as an average.

Measurement of physical properties of cooked milled rice grains The milled rice samples $(10 \mathrm{~g})$ were added with $16 \mathrm{~g}$ of distilled water in an aluminum cup $(55 \times 40 \times 55 \mathrm{~mm})$. After soaking for $1 \mathrm{~h}$, the samples were cooked in an electric rice cooker (RC183, Toshiba Co., Ltd, Tokyo). The cups were covered with two kinds of sheets, an outer sheet of aluminum foil, and an inner sheet of paper for the absorption of excess vapor to prevent moisture loss from the grains after cooking, and were sealed in an airtight plastic vessel. The cooked rice samples were kept in the vessel for about $2 \mathrm{~h}$ at room temperature $\left(25^{\circ} \mathrm{C}\right)$ and used for measurements.

The hardness and stickiness of cooked milled rice grains were measured with a Tensipresser (My Boy System, Taketomo Electric Co., Tokyo) by the individual grain method with low compression (25\%) and high compression (95\%) test (Okadome et al., 2001). The conditions for measurement were as follows: grains to be measured, 1 grain in one time measurement; repeated bites and speed, 2 time and $6.0 \mathrm{~mm} / \mathrm{s}$; load cell, maximum $10 \mathrm{kgf}$; deformation (compression) rate, $25 \%$ and $90 \%$. The measurement was conducted 20 times (20 grains), and the result was expressed as an average \pm standard deviation. The physical properties of cooked rice grains were also measured using a Texturometer (Zenken Co., Tokyo) by the three grain method (Okabe, 1979). The conditions for measurement were as follows: grains to be measured, 3; repeated bites and speed, 2 cycles and $20 \mathrm{~s}$; load cell, maximum $25 \mathrm{kgf}$; clearance, $0.2 \mathrm{~mm}$, and sample temperature at the time of measurement, $25^{\circ} \mathrm{C}$. The most important parameter, the stickiness/hardness ratio (balance degree, $-\mathrm{H}_{1} / \mathrm{H}_{1}$ ) proposed by Okabe (1979) was also determined. Measurements were made 5 times, and the result was expressed as an average \pm standard deviation.
Cooking quality characteristics of milled rice The characteristics of cooked rice were determined by Batcher method (Batcher et al., 1956). Eight gram of head milled rices were cooked with $160 \mathrm{ml}$ distilled water, and after cooking the rice was measured for water uptake ratio (WUR), expanded volume (EV), $\mathrm{pH}$, and iodine blue value (IBV). Analysis was conducted on duplicates of each sample and the result was calculated as an average.

Pasting properties of milled rice flours A Rapid-ViscoAnalyzer (RVA) model 3D (Newport Scientific Pty., Ltd., Warriewood, New South Wales, Australia) was employed to determine the pasting properties of the various rice flours. The sample $(3.5 \mathrm{~g})$ was made equivalent to $14 \%$ moisture and mixed with water in an RVA aluminum canister (supplied by Newport Scientific Pty., Ltd.,) to make the total weight of the slurry $28 \mathrm{~g}$. A programmed heating and cooling cycle was followed as outlined in the procedure of Toyoshima et al. (1997). The sample was installed on the rotor of the RVA and heated from 50 to $93^{\circ} \mathrm{C}$ (at $50^{\circ} \mathrm{C}$ for $1 \mathrm{~min}$ and $4 \mathrm{~min}$ to reach $93^{\circ} \mathrm{C}$ ). It was held at $93^{\circ} \mathrm{C}$ for $7 \mathrm{~min}$, cooled from 93 to $50^{\circ} \mathrm{C}$ over $4 \mathrm{~min}$, and allowed to stand at $50^{\circ} \mathrm{C}$ for $3 \mathrm{~min}$. Parameters recorded were maximum (peak), minimum, and final viscosity, setback, breakdown, pasting temperature, and peak time.

Amylase activity $\alpha$-Amylase and $\beta$-amylase activity of milled rice were determined using the kits of Megazyme International Ireland, Ltd. For $\alpha$-amylase activity measurement, rice flour $\left(1.5 \mathrm{~g}\right.$ ) was extracted with Tris buffer, $\mathrm{pH}-5.4$ at $40^{\circ} \mathrm{C}$ for 20 $\mathrm{min}$, then centrifuged for $10 \mathrm{~min}$ at $1000 \times \mathrm{g}$. The clear supernatant was used for the micro-assay of $\alpha$-amylase activity which was carried out using the amylase HR Reagent (Ceralpha method, Megazyme International Ireland, Ltd.,). For $\beta$-amylase activity measurement, rice flour ( $1.5 \mathrm{~g})$ was extracted with Tris buffer, $\mathrm{pH}-8.0$ at room temperature for $1 \mathrm{~h}$, then centrifuged for $10 \mathrm{~min}$ at $1000 \times \mathrm{g}$. The clear supernatant was used for the micro-assay of $\beta$-amylase activity, which was carried out using the Betamyl Reagent (Betamyl method, Megazyme International Ireland, Ltd., Wicklow, Ireland). Duplicate analyses were made of each sample and the result was calculated as an average.

\section{Instrumental tests}

Whiteness of milled rice The whiteness of milled rice was measured using a Whiteness Meter (Kett Electric Laboratory C300-3, Tokyo).

Color difference of milled rice The color of the milled rice was measured by a Color Difference Meter (Minolta Spectrophotometer CM-3500d, Osaka). Obtained parameters were $(L)$ for lightness, $(b)$ for yellow color, and $(a)$ for red color of milled rice samples.

Glossiness of milled rice The glossiness of milled rice grains was measured by a Digital Variable Gloss Meter (UGV-5D, SUGA Test Instruments Co., Tokyo)

Main chemical components Main chemical components (moisture, protein and amylose content) of milled rice were determined with a "Taste Analyzer" (Rice analyzer RQ $\mathrm{Q}_{1}$-Plus, Shimadzu Corporation, Kyoto).

Taste score (Mido score) Taste score (Mido score) of milled rice samples was measured using a Toyo Mido Meter MB-90A, Wakayama.

All the above instrumental measurements were made in duplicate and the result was calculated as an average. 


\section{Results and Discussion}

Main chemical components During storage, rice quality is greatly affected by moisture content. The higher the amount of moisture, the faster the rate of quality deterioration. Therefore, the moisture content of rice should be kept at a safe level. Aside from storage, moisture content is also an important factor for milling characteristics, processing, and sensory quality of rice (Juliano et al., 1981). As shown in Table 2, the Vietnamese rice varieties have moisture content ranging from $12.8-15.2 \%$ while those of the Japanese rice varieties range from $13.8-14.4 \%$. All the samples were therefore suitable for storage.

Amylose is one of the two components of rice starch which greatly affects the quality and gelatinization properties of cooked rice. Generally, rice containing low amylose becomes soft and sticky upon cooking while rice containing high amylose becomes hard and separated. Based on amylose content, milled rice is classified as glutinous: $0-5 \%$, very low: $5.1-10.0 \%$, low: $10.1-$ $20 \%$, intermediate: $20.1-25 \%$, high: $>25 \%$ (Juliano \& Villareal, 1993). Since the longer grain varieties have higher amylose content, this difference in starch composition is possibly responsible for the known difference in cooking quality. Cooked glutinous and japonica rice are characteristically moist and sticky, whereas indica rice is dry and flaky. The higher amylopectin content, which is of low-amylose variety, may explain why its cooked grain is more cohesive than that of high-amylose rice. As Japanese consumers prefer soft and sticky cooked rice, low amylose rice is dominant in the Japanese market. Based on the classification by amylose content of Juliano and Villareal (1993), 4 rice varieties are glutinous; 1 variety is very low amylose; 4 varieties are low amylose, and 11 varieties are high amylose. Except Nep cai hoa vang, Nep thuy tien, and IR352 of glutinous rice, all the other Vietnamese rices belong to the high and intermediate amylose classes. Vietnamese aromatic, local varieties are Tam ap be, Bac huong, and Tam xoan which are most favored in Vietnam, and do not have a high amylose content: $15.7-28.1 \%$. Among Japanese rice varieties, Hoshinishiki is characterized as having exceptionally high amylose content; it does not have good eating characteristics as viewed by Japanese standards but is suitable for processing rice flour, pilaf, rice noodles or curry rice. Koshihikari
(17.7\%) and Nipponbare (19.1\%) are considered to have the best and intermediate eating quality in Japan. The glutinous rice varieties have specified amylose content: Vietnamese rices are $2.8 \%$, $3.0 \%$, and $1.9 \%$, while Japanese rice is nil $(-0.7 \%)$.

Protein is the second most abundant constituent of milled rice, following starch. Aside from the inherent difference of protein content among rice varieties, the other factors that influence its amount are fertilization, soil, and water control (Ohtsubo, 1995). In general, the crude protein of milled rice is distributed between 5 to $15 \%$. Since milled rice is still known to be the major source of dietary protein in many Asian and developing countries (including Vietnam), it is important to consider this index of nutritional value in the breeding program. The amount of protein affects the physical properties of the rice: the higher the protein content, the harder and less sticky the rice becomes upon cooking (Okadome et al., 1999). Vietnamese rice varieties have an average protein content of $7.8 \%(6.6-10.5 \%)$, higher than Japanese rice varieties which average $6.9 \%(5.5-8.1 \%)$. This reflects that milled rice is still the principal source of dietary protein in Vietnam. Among Japanese rices, the glutinous rice Hiyokumochi has the highest protein content, $8.1 \%$, while Koshihikari has the lowest, $5.5 \%$. Vietnamese local aromatic rice tends to have a high protein content ranging from $8.5-10.5 \%$.

One of the chemical changes that occurs during storage of rice is the increase in fat acidity. This is therefore considered an important index for measuring quality deterioration during storage (Ohtsubo et al., 1987). Fat acidity has been measured by the AACC titration method but due to a number of problems associated with it, a new colorimetric method was developed by Ohtsubo et al. (1987). This modified Duncombe method (Duncombe, 1963) is sensitive and reproducible and is applicable to both brown rice and milled rice. Table 2 shows the fat acidity of the rice samples analyzed. Among the 20 samples, the highest amount (IR 352: $89.4 \mathrm{mg} \mathrm{KOH} / 100 \mathrm{~g}$ flour) was found in the Vietnamese glutinous rice variety. The Japanese glutinous rice variety, Hiyokumochi was also high in fat acidity $(50.0 \mathrm{mg} \mathrm{KOH} /$ $100 \mathrm{~g}$ flour). This is in accordance with Taira (1985) who reported that the total lipid content in glutinous rice is higher than in non-glutinous rice. It is also seen from Table 2 that most Viet-

Table 2. Main chemical components and amylase activities of samples.

\begin{tabular}{|c|c|c|c|c|c|c|c|}
\hline No & Sample & Moisture (\%) & Amylose (\%) & Protein $(\%)$ & Fat Acidity (mgKOH/100g d.w flour) & Alpha (CU/g flour) & Beta (BU/g flour) \\
\hline 1 & P4 & 13.8 & 13.7 & 7.8 & 15.5 & 0.036 & 0.095 \\
\hline 2 & Tam Ap Be & 12.8 & 28.1 & 10.5 & 18.3 & 0.042 & 0.316 \\
\hline 3 & Bac Huong & 15.2 & 15.7 & 8.5 & 52.1 & 0.062 & 0.139 \\
\hline 4 & Tam Xoan & 14.3 & 26.8 & 10.0 & 30.6 & 0.051 & 0.239 \\
\hline 5 & Nep Cai Hoa Vang & 14.3 & 2.8 & 6.8 & 47.9 & 0.030 & 0.163 \\
\hline 6 & Nep Thuy Tien & 13.6 & 3.0 & 7.2 & 66.9 & 0.024 & 0.176 \\
\hline 7 & IR64 & 13.9 & 30.6 & 9.8 & 22.7 & 0.021 & 0.256 \\
\hline 8 & Ai32 & 13.2 & 39.7 & 6.6 & 23.0 & 0.037 & 0.175 \\
\hline 9 & $\mathrm{X} 21$ & 13.8 & 28.1 & 6.6 & 37.7 & 0.043 & 0.227 \\
\hline 10 & Q5 & 13.9 & 36.2 & 6.7 & 49.8 & 0.052 & 0.331 \\
\hline 11 & $\mathrm{C} 70$ & 13.0 & 38.0 & 6.8 & 11.8 & 0.012 & 0.153 \\
\hline 12 & Khang Dan & 13.6 & 37.1 & 6.7 & 74.9 & 0.046 & 0.248 \\
\hline 13 & XI23 & 13.5 & 28.2 & 7.5 & 38.4 & 0.047 & 0.207 \\
\hline 14 & $108 \mathrm{AV}$ & 13.9 & 38.4 & 6.9 & 34.5 & 0.033 & 0.168 \\
\hline 15 & IR352 & 13.8 & 1.9 & 7.8 & 89.4 & 0.042 & 0.197 \\
\hline 16 & Koshihikari & 14.4 & 17.7 & 5.5 & 26.1 & 0.037 & 2.204 \\
\hline 17 & Hiyokumochi & 14.1 & -0.7 & 8.1 & 50.0 & 0.062 & 0.851 \\
\hline 18 & Hoshinishiki & 14.2 & 31.0 & 6.4 & 9.0 & 0.023 & 0.416 \\
\hline 19 & Nipponbare & 13.9 & 19.1 & 7.5 & 16.7 & 0.029 & 0.341 \\
\hline 20 & Milkyqueen & 13.8 & 9.7 & 6.9 & 10.8 & 0.020 & 0.698 \\
\hline
\end{tabular}

$\mathrm{CU} / \mathrm{g}$ flour: Ceralpha units per one gram milled rice flour; BU/g flour: Betamyl units per one gram milled rice flour 
namese rice has fat acidity values higher than that of Japanese rice. These results indicate that the Vietnamese rice samples used may have been slightly old while the Japanese rice samples were still very fresh. We had considered this to be the cause before we received the Vietnamese rice samples that had been preserved at higher temperature than the Japanese; therefore, the Vietnamese samples had aged more quickly than the Japanese samples.

The palatability and acceptability of rice are greatly affected by the physical properties of hardness and stickiness (Okabe, 1979). Aside from the widely used texturometer, many instruments are now utilized to determine the physical properties of cooked rice. These include the Instron food tester, texture analyzer, food rheometer, and others. A number of research findings have also been published regarding the use of texture measuring devices in assessing cooked rice texture in lieu of sensory evaluation. Among the more recent are the works of Okadome et al. (1996, 1999, 2001). A new Tensipresser model has been successfully used in discriminating japonica rice of similar starch properties. Due to the high load cell sensitivity, this instrument is able to determine the parameters using only one grain of cooked rice. In addition, sample thickness can be measured automatically. Since the compression ratio of the Tensipresser can be adjusted, it is possible to use it for different kinds of tests such as low compression test (LCT), and high-compression test (HCT). LCT, which uses $25 \%$ compression, measures the hardness and stickiness of the surface layer of cooked rice while HCT, with $90 \%$ compression, measures the overall properties of the grain. Aside from hardness and stickiness, these tests can be used to determine other parameters such as palatability, brittleness, toughness, etc. The data for hardness, stickiness, and their ratio (balance degree) for both LCT and HCT are shown in Table 3(a). The LCT results showed that almost all of the Vietnamese non-glutinous rice samples were harder than the Japanese non-glutinous rice. In general, the higher the amylose content of the rice sample, the higher the hardness value of cooked grains. From the surface stickiness data, the Vietnamese non-glutinous rice variety, Khang dan $\left(0.49 \times 10^{3} \mathrm{dyn}\right)$ and the Japanese low amylose Milkyqueen $\left(25.50 \times 10^{3} \mathrm{dyn}\right)$ were found to be the least and most

Table 3(a). Physical properties of cooked milled rice using Tensipresser.

\begin{tabular}{|c|c|c|c|c|c|c|c|c|}
\hline \multirow[b]{2}{*}{ No } & \multirow[b]{2}{*}{ Sample } & \multicolumn{3}{|c|}{ Low compression test } & \multicolumn{3}{|c|}{ High compression test } & \multirow{2}{*}{$\begin{array}{c}\text { Sample } \\
\text { thickness } \\
(\mathrm{mm})\end{array}$} \\
\hline & & $\begin{array}{l}\text { Hardness }\left(\mathrm{H}_{1}\right) \\
\left(10^{4} \text { dyn }\right)\end{array}$ & $\begin{array}{l}\text { Stickiness }\left(-\mathrm{H}_{2}\right) \\
\left(10^{3} \mathrm{dyn}\right)\end{array}$ & $\begin{array}{l}\text { Balance } \\
\left(-\mathrm{H}_{1} / \mathrm{H}_{1}\right)\end{array}$ & $\begin{array}{l}\text { Hardness }\left(\mathrm{H}_{2}\right) \\
\left(10^{6} \text { dyn }\right)\end{array}$ & $\begin{array}{l}\text { Stickiness }\left(-\mathrm{H}_{2}\right) \\
\left(10_{5} \mathrm{dyn}\right)\end{array}$ & $\begin{array}{l}\text { Balance } \\
\left(-\mathrm{H}_{2} / \mathrm{H}_{2}\right)\end{array}$ & \\
\hline 1 & $\mathrm{P} 4$ & $6.89 \pm 2.16$ & $14.10 \pm 5.54$ & $0.21 \pm 0.07$ & $1.90 \pm 0.26$ & $4.61 \pm 0.56$ & $0.25 \pm 0.06$ & $2.23 \pm 0.10$ \\
\hline 2 & Tam Ap Be & $8.21 \pm 1.59$ & $7.53 \pm 2.51$ & $0.09 \pm 0.03$ & $2.50 \pm 0.23$ & $2.69 \pm 0.40$ & $0.11 \pm 0.02$ & $1.89 \pm 0.11$ \\
\hline 3 & Bac Huong & $8.57 \pm 2.02$ & $14.50 \pm 5.55$ & $0.17 \pm 0.06$ & $1.88 \pm 0.39$ & $3.60 \pm 0.76$ & $0.21 \pm 0.07$ & $1.94 \pm 0.14$ \\
\hline 4 & Tam Xoan & $8.98 \pm 2.16$ & $10.40 \pm 5.05$ & $0.12 \pm 0.06$ & $2.34 \pm 0.45$ & $3.12 \pm 0.90$ & $0.15 \pm 0.07$ & $1.98 \pm 0.12$ \\
\hline 5 & Nep Cai Hoa Vang & $4.88 \pm 0.80$ & $7.89 \pm 5.03$ & $0.15 \pm 0.07$ & $1.45 \pm 0.15$ & $5.33 \pm 0.46$ & $0.37 \pm 0.03$ & $2.14 \pm 0.14$ \\
\hline 6 & Nep Thuy Tien & $5.34 \pm 1.06$ & $8.92 \pm 5.79$ & $0.16 \pm 0.09$ & $1.60 \pm 0.20$ & $5.66 \pm 0.40$ & $0.36 \pm 0.03$ & $2.19 \pm 0.15$ \\
\hline 7 & IR64 & $13.20 \pm 2.37$ & $8.58 \pm 2.74$ & $0.07 \pm 0.02$ & $3.18 \pm 0.47$ & $3.23 \pm 1.00$ & $0.11 \pm 0.05$ & $2.25 \pm 0.10$ \\
\hline 8 & Ai32 & $11.20 \pm 2.17$ & $1.26 \pm 1.25$ & $0.01 \pm 0.01$ & $3.21 \pm 0.32$ & $1.55 \pm 0.66$ & $0.05 \pm 0.02$ & $2.29 \pm 0.14$ \\
\hline 9 & $\mathrm{X} 21$ & $8.93 \pm 2.05$ & $7.13 \pm 2.95$ & $0.08 \pm 0.03$ & $2.94 \pm 0.19$ & $2.84 \pm 0.38$ & $0.10 \pm 0.01$ & $2.17 \pm 0.09$ \\
\hline 10 & Q5 & $10.40 \pm 2.00$ & $1.23 \pm 1.05$ & $0.01 \pm 0.01$ & $3.36 \pm 0.35$ & $1.04 \pm 0.38$ & $0.03 \pm 0.01$ & $2.48 \pm 0.09$ \\
\hline 11 & C70 & $10.80 \pm 2.41$ & $2.67 \pm 1.92$ & $0.02 \pm 0.01$ & $3.19 \pm 0.45$ & $1.28 \pm 0.58$ & $0.04 \pm 0.02$ & $2.09 \pm 0.12$ \\
\hline 12 & Khang Dan & $9.04 \pm 3.09$ & $0.49 \pm 0.43$ & $0.01 \pm 0.00$ & $2.66 \pm 0.40$ & $0.80 \pm 0.26$ & $0.03 \pm 0.01$ & $2.13 \pm 0.20$ \\
\hline 13 & $\mathrm{XI} 23$ & $9.84 \pm 2.44$ & $7.47 \pm 4.00$ & $0.08 \pm 0.03$ & $2.68 \pm 0.27$ & $2.59 \pm 0.61$ & $0.10 \pm 0.03$ & $2.24 \pm 0.15$ \\
\hline 14 & $108 \mathrm{AV}$ & $10.90 \pm 2.38$ & $1.52 \pm 1.18$ & $0.00 \pm 0.01$ & $2.82 \pm 0.38$ & $1.00 \pm 0.44$ & $0.04 \pm 0.02$ & $2.26 \pm 0.11$ \\
\hline 15 & IR352 & $4.57 \pm 0.79$ & $7.05 \pm 2.63$ & $0.15 \pm 0.05$ & $1.31 \pm 0.11$ & $3.97 \pm 0.30$ & $0.30 \pm 0.02$ & $2.14 \pm 0.08$ \\
\hline 16 & Koshihikari & $6.30 \pm 1.55$ & $18.00 \pm 7.96$ & $0.28 \pm 0.09$ & $2.05 \pm 0.31$ & $4.95 \pm 0.34$ & $0.25 \pm 0.06$ & $2.28 \pm 0.17$ \\
\hline 17 & Hiyokumochi & $4.40 \pm 0.90$ & $5.87 \pm 3.21$ & $0.13 \pm 0.06$ & $1.52 \pm 0.14$ & $5.27 \pm 0.37$ & $0.35 \pm 0.02$ & $2.36 \pm 0.14$ \\
\hline 18 & Hoshinishiki & $9.00 \pm 1.22$ & $9.55 \pm 3.68$ & $0.10 \pm 0.03$ & $2.82 \pm 0.44$ & $3.32 \pm 0.62$ & $0.13 \pm 0.05$ & $2.26 \pm 0.11$ \\
\hline 19 & Nipponbare & $10.00 \pm 2.09$ & $21.50 \pm 5.23$ & $0.22 \pm 0.06$ & $2.45 \pm 0.29$ & $4.76 \pm 0.46$ & $0.20 \pm 0.04$ & $2.18 \pm 0.14$ \\
\hline 20 & Milkyqueen & $7.72 \pm 1.55$ & $25.50 \pm 5.38$ & $0.33 \pm 0.06$ & $2.06 \pm 0.24$ & $5.29 \pm 0.40$ & $0.26 \pm 0.02$ & $2.06 \pm 0.13$ \\
\hline
\end{tabular}

Table 3(b). Physical properties of cooked milled rice using Texturometer.

\begin{tabular}{|c|c|c|c|c|c|}
\hline No & Sample & Hardness $\left(\mathrm{H}_{1}\right)(\mathrm{kgf})$ & Stickiness $\left(-\mathrm{H}_{1}\right)(\mathrm{kgf})$ & Balance $\left(-\mathrm{H}_{1} / \mathrm{H}_{1}\right)$ & Cooked milled rice Moisture (\%) \\
\hline 1 & $\mathrm{P} 4$ & $2.69 \pm 0.13$ & $0.64 \pm 0.15$ & $0.24 \pm 0.05$ & 64.2 \\
\hline 2 & Tam Ap Be & $2.81 \pm 0.08$ & $0.00 \pm 0.00$ & $0.00 \pm 0.00$ & 63.8 \\
\hline 3 & Bac Huong & $2.23 \pm 0.10$ & $0.33 \pm 0.08$ & $0.15 \pm 0.04$ & 65.2 \\
\hline 4 & Tam Xoan & $2.83 \pm 0.23$ & $0.00 \pm 0.00$ & $0.00 \pm 0.00$ & 64.0 \\
\hline 5 & Nep Cai Hoa Vang & $1.96 \pm 0.05$ & $0.87 \pm 0.08$ & $0.44 \pm 0.04$ & 63.8 \\
\hline 6 & Nep Thuy Tien & $2.08 \pm 0.22$ & $0.79 \pm 0.02$ & $0.38 \pm 0.04$ & 63.9 \\
\hline 7 & IR64 & $3.98 \pm 0.17$ & $0.00 \pm 0.00$ & $0.00 \pm 0.00$ & 64.9 \\
\hline 8 & Ai32 & $3.71 \pm 0.22$ & $0.00 \pm 0.00$ & $0.00 \pm 0.00$ & 64.4 \\
\hline 9 & $\mathrm{X} 21$ & $3.51 \pm 0.14$ & $0.08 \pm 0.00$ & $0.02 \pm 0.00$ & 64.3 \\
\hline 10 & Q5 & $4.13 \pm 0.16$ & $0.00 \pm 0.00$ & $0.00 \pm 0.00$ & 65.2 \\
\hline 11 & $\mathrm{C} 70$ & $3.83 \pm 0.21$ & $0.00 \pm 0.00$ & $0.00 \pm 0.00$ & 63.7 \\
\hline 12 & Khang Dan & $3.28 \pm 0.21$ & $0.00 \pm 0.00$ & $0.00 \pm 0.00$ & 65.3 \\
\hline 13 & $\mathrm{XI} 23$ & $3.43 \pm 0.19$ & $0.00 \pm 0.00$ & $0.00 \pm 0.00$ & 65.7 \\
\hline 14 & $108 \mathrm{AV}$ & $3.61 \pm 0.12$ & $0.00 \pm 0.00$ & $0.00 \pm 0.00$ & 64.1 \\
\hline 15 & IR352 & $2.05 \pm 0.10$ & $0.86 \pm 0.07$ & $0.42 \pm 0.04$ & 65.5 \\
\hline 16 & Koshihikari & $2.55 \pm 0.11$ & $0.49 \pm 0.20$ & $0.20 \pm 0.08$ & 64.2 \\
\hline 17 & Hiyokumochi & $1.93 \pm 0.14$ & $0.76 \pm 0.06$ & $0.39 \pm 0.03$ & 65.9 \\
\hline 18 & Hoshinishiki & $3.44 \pm 0.12$ & $0.00 \pm 0.00$ & $0.00 \pm 0.00$ & 64.1 \\
\hline 19 & Nipponbare & $2.87 \pm 0.11$ & $0.25 \pm 0.03$ & $0.09 \pm 0.01$ & 65.2 \\
\hline 20 & Milkyqueen & $2.46 \pm 0.19$ & $0.52 \pm 0.06$ & $0.21 \pm 0.04$ & 64.5 \\
\hline
\end{tabular}


Table 4. Correlation between amylose content with cooking quality, pasting, and physical parameters.

\begin{tabular}{lcc}
\hline Parameter & Japanese rice & Vietnamese rice \\
\hline EV & 0.88 & $0.84^{* *}$ \\
IBV & $0.96^{* *}$ & $0.82^{* *}$ \\
Hardness & $0.96^{* *}$ & $0.94^{* *}$ \\
Stickiness & -0.87 & $-0.92^{* *}$ \\
Balance degree & $-0.98^{* *}$ & $-0.98^{* *}$ \\
Time to peak & $0.89^{*}$ & $0.90^{* *}$ \\
Maximum visc. & 0.47 & $0.76^{* *}$ \\
Final visc. & $0.92^{*}$ & $0.97^{* *}$
\end{tabular}

Correlation significant $*$ and $* *$ at $5 \%$ and $1 \%$, respectively.

adhesive rice samples, respectively. The stickiness/hardness ratio $\left(-\mathrm{H}_{1} / \mathrm{H}_{1}\right.$, balance degree) ranged from 0.01 to 0.33 . On the other hand, the overall texture property data revealed that the most tender rice sample was the glutinous rice variety. The balance degree ranged from 0.03 to 0.37 . Using the Texturometer, the texture of cooked rice is based on the major parameters of hardness $\left(\mathrm{H}_{1}\right)$ and stickiness $\left(-\mathrm{H}_{1}\right)$ which influence the eating quality (Table 3(b)). The ratio of $-\mathrm{H}_{1}$ and $\mathrm{H}_{1}\left(-\mathrm{H}_{1} / \mathrm{H}_{1}\right)$ or balance degree is an important index in evaluating the palatability of rice in Japan (Okabe, 1979) which is viewed as highly acceptable if the value is $0.15-0.20$ with lower values associated with inferior rice. The texture of cooked rice was very well correlated with amylose content (Juliano et al., 1981), especially for high-amylose rice, thus amylose provides an excellent characterization of texture. Both Vietnamese and Japanese rices have significant correlation between amylose content and texture parameters $\left(\mathrm{H}_{2}\right.$, $-\mathrm{H}_{2}$, and $\left.-\mathrm{H}_{2} / \mathrm{H}_{2}\right), r=0.94 ;-0.92$; and -0.98 for Vietnamese and $r=0.96$; -0.87 ; and -0.98 for Japanese (Table 4). Hardness of cooked rice usually increases with the increase of amylose content. Belonging to the intermediate to high amylose class, Vietnamese rices thus are characterized as having high hardness value with $\mathrm{H}_{1}$ ranging from $2.81 \mathrm{kgf}$ to $4.13 \mathrm{kgf}$ and low stickiness value with $-\mathrm{H}_{1}=0.00$, in comparison with Japanese rice which has $\mathrm{H}_{1}=2.46$ to 3.44 and $-\mathrm{H}_{1}=0.25$ to 0.52 . Among Japanese rices, higher amylose content Hoshinishiki has higher hardness $\left(\mathrm{H}_{1}=3.44 \mathrm{kgf}\right)$ and lower stickiness $\left(-\mathrm{H}_{1}=0.00\right)$. All glutinous rice varieties are characterized by having low hardness and high stickiness values (Table 3). The Tensipresser HCT was similar to the conventional Texturometer method with three cooked rice grains (Okabe, 1979) at the point of the large deformation. The Tensipresser hardness revealed a high correlation with the Texturometer hardness when only glutinous rice samples were used (Ohtsubo et al., 1998). Okadome's research included glutinous and waxy rice samples and also showed a positive correlation (Okadome et al., 1999). Therefore, the HCT test measuring a single grain using a Tensipresser obtained the same hardness results as the three-grain method using a Texturometer.

Cooking quality characteristics In Japan, cooking quality of rice is usually assessed by the Batcher's method (Batcher et $a l .$, 1956). The important parameters are expanded volume (EV), water uptake ratio (WUR), iodine blue value (IBV) of residual liquid and $\mathrm{pH}$. Grain type is factor influencing the water absorption since most long grain varieties absorbed more water than medium and short grain types. The water absorption and swelling of rice during cooking may be functions of the surface area of the kernel aside from other physicochemical considerations. Vietnamese long grain non-glutinous rice has higher WUR on average at $380 \%$ (344\% to $439 \%$ ), compared to Japanese nonglutinous rice: $332 \%$ (322\% to $339 \%$ ). Glutinous rice has lower EV than non-glutinous rice. Cooking quality is strongly influenced by the amylose content of the starch. High amylose rice generally absorbs more water and expands more during cooking than low amylose rice. In general, the iodine blue value of residual liquid (IBV) of long grain rice is higher than that of short and medium grain rice. Vietnamese rice has IBV of 0.27 on average, while Japanese rice is 0.22 . IBV is influenced by amylose content and the correlation is 0.96 and 0.82 for Japanese and Vietnamese rice, respectively (Table 4). Most rice residual liquid had $\mathrm{pH}$ values between 6.0 to 6.7 (Table 5).

Pasting properties of milled rice flours Since pasting properties influence rice eating quality, it is necessary to conduct a gelatinization test. Brabender viscoamylography has traditionally been used to determine starch pasting and setback characteristics. However, this method has several disadvantages such as large sample requirement, long analysis time, and high cost of

Table 5. Cooking characteristics of samples.

\begin{tabular}{|c|c|c|c|c|c|}
\hline No & Sample & Water uptake ratio $(\%)$ & Expanded volume $\left(\mathrm{cm}^{3}\right)$ & $\mathrm{pH}$ & Iodine blue value \\
\hline 1 & $\mathrm{P} 4$ & 370 & 42.9 & 6.09 & 0.18 \\
\hline 2 & Tam Ap Be & 359 & 43.2 & 6.12 & 0.33 \\
\hline 3 & Bac Huong & 389 & 47.4 & 6.00 & 0.21 \\
\hline 4 & Tam Xoan & 374 & 46.5 & 6.01 & 0.36 \\
\hline 5 & Nep Cai Hoa Vang & 374 & 35.5 & 6.06 & 0.09 \\
\hline 6 & Nep Thuy Tien & 343 & 33.3 & 6.21 & 0.09 \\
\hline 7 & IR64 & 344 & 46.2 & 6.42 & 0.33 \\
\hline 8 & Ai32 & 362 & 45.2 & 6.59 & 0.30 \\
\hline 9 & $\mathrm{X} 21$ & 426 & 49.7 & 6.44 & 0.44 \\
\hline 10 & Q5 & 352 & 47.8 & 6.55 & 0.30 \\
\hline 11 & C70 & 439 & 56.5 & 6.40 & 0.34 \\
\hline 12 & Khang Dan & 407 & 52.1 & 6.65 & 0.31 \\
\hline 13 & $\mathrm{XI} 23$ & 385 & 46.4 & 6.58 & 0.34 \\
\hline 14 & $108 \mathrm{AV}$ & 353 & 47.9 & 6.60 & 0.26 \\
\hline 15 & IR352 & 367 & 36.8 & 6.69 & 0.10 \\
\hline 16 & Koshihikari & 334 & 38.3 & 6.38 & 0.21 \\
\hline 17 & Hiyokumochi & 336 & 34.2 & 6.63 & 0.10 \\
\hline 18 & Hoshinishiki & 333 & 41.2 & 6.56 & 0.41 \\
\hline 19 & Nipponbare & 322 & 40.1 & 6.40 & 0.25 \\
\hline 20 & Milkyqueen & 339 & 39.3 & 6.52 & 0.13 \\
\hline
\end{tabular}


equipment. The Rapid-Visco-Analyzer (RVA) was therefore developed by the Australian CSIRO Wheat Research Unit and Bread Research Institute to screen wheat samples for sprout damage (Ross et al., 1987). Some modifications enable RVA to determine the cooking properties of starch and starch-containing products (Walker et al., 1988). RVA, which is a product of Newport Scientific, is now used to assess the viscosity of any material where the cooked viscosity is important, and the RVA test for rice was adopted as an AACC approved method (AACC. Official Method 61-02, 1995). The test involves gelatinization of the starch with consequent increase in viscosity, increase in temperature, controlled shear, and, finally, cooling down to determine setback during gelation. The viscosity unit is the Rapid Visco Unit (RVU) which is defined as a torque fastened by a paddle to the stirring motor (RVA User's Manual, 1996). The gelatinization data are shown in Table 6. Peak viscosity is the maximum viscosity due to swelling during the heating stage. A high peak viscosity indicates the ease with which the starch granules are disintegrated. As Juliano reported, indica rice has a higher maximum viscosity than japonica rice, the mean value of Vietnamese rice being $375.96 \mathrm{RVU}$ on average, compared to $328.67 \mathrm{RVU}$ of Japanese rice. Final viscosity, however, is related to the degree of starch retrogradation upon cooling. In general, rice with high amylose content also has high final viscosity. High amylose Vietnamese rices Ai32, Khang dan, C70, and 108AV showed high final viscosities. A high positive significant correlation between final viscosity and amylose content was found in both Vietnamese and Japanese rice ( $r=0.97$ and 0.92 , Table 4). Breakdown is the difference between the peak and trough viscosity. Rice with higher breakdown is believed to have better palatability. Among Japanese rices, the highest value was obtained for Milkyqueen, which was also indicated to be the most palatable based on the peak viscosity. This particular new variety is popular in Japan because of its good eating quality. Pasting temperature is a physical property reported to be highly correlated with the other quality tests. Rice varieties with starch pasting temperature below $70^{\circ} \mathrm{C}$ are classified as low and intermediate: between $70^{\circ} \mathrm{C}$ to $74^{\circ} \mathrm{C}$, and high: $75^{\circ} \mathrm{C}$ and higher. In general, the long grain varieties gelatinized at higher pasting temperature than the short and medium grain type. Japanese rice varieties had lower pasting temperature $\left(72.16^{\circ} \mathrm{C}\right.$ on average) than Vietnamese varieties $\left(74.79^{\circ} \mathrm{C}\right.$ on average). Determination of pasting temperature is useful where the rice is used as a secondary source of carbohydrate in brewing. The low pasting temperature should be of interest to brewers and cereal manufacturers who use diastatic digestion in their process because a low pasting temperature allows complete liquefaction of starch before thermal inactivation of the enzyme can occur. There is positive significant correlation between time to peak and amylose content in both Vietnamese and Japanese rices ( $r=0.90$ and 089, Table 4). Among all the viscosity parameters, those from glutinous rice are much lower than those of non-glutinous rice, which is probably due to the high content of water-soluble polysaccharides; the Japanese rice, Hiyokumochi, exhibited the lowest values.

Amylase activity $\alpha$-Amylases are enzymes that cleave the $\alpha-(1-4)$ D-glucosidic linkages in starch components. The cleavage is believed to be restricted by terminal or $\alpha-(1-6)$ inter-chain linkages. The level of endogenous $\alpha$-amylase in cereal grains and products significantly affects the industrial exploitation of these commodities. The exact contribution of $\alpha$-amylase activity to rice grain quality is not yet clear. Some conflicting findings have been reported in the past about the influence of the said enzyme to cooked rice texture. High $\alpha$-amylase activities were observed in Japanese glutinous rice (Hiyoukumochi $0.062 \mathrm{CU} / \mathrm{g}$ ) and Vietnamese aromatic local rice (ranging from 0.042 to $0.062 \mathrm{CU} / \mathrm{g}$, Table 2).

$\beta$-Amylases play a central role in the complete degradation of starch to metabolizable or fermentable sugars during the germination or malting of cereal grains. They also find considerable application, together with starch debranching enzymes, in the production of high maltose syrups. $\beta$-Amylases cleave alternate $\alpha-(1-4)$ D-glucosidic linkages in starch components in a stepwise fashion from the non-reducing end, resulting in the production of $\beta$-maltose. The reaction of the enzyme stops in the region of $\alpha$ (1-6) D-glucosidic linkages. The $\alpha$-amylase and $\beta$-amylase activity data are shown in Table 2 . Among all the samples, Japanese rice variety Koshihikari showed the highest activity at 0.851 $\mathrm{BU} / \mathrm{g}$ and the $\beta$-amylase activity of Japanese rice was found to

Table 6. Pasting characteristics of milled rice flours.

\begin{tabular}{|c|c|c|c|c|c|c|}
\hline No & Sample & Maximum visc. (RVU) & Breakdown (RVU) & Final visc. (RVU) & Setback (RVU) & Pasting temp. $\left({ }^{\circ} \mathrm{C}\right)$ \\
\hline 1 & $\mathrm{P} 4$ & 420.33 & 273.92 & 252.08 & 105.67 & 83.00 \\
\hline 2 & Tam Ap Be & 267.25 & 105.33 & 334.25 & 172.33 & 76.55 \\
\hline 3 & Bac Huong & 384.83 & 248.42 & 267.25 & 130.83 & 77.20 \\
\hline 4 & Tam Xoan & 298.33 & 149.67 & 327.00 & 178.33 & 77.35 \\
\hline 5 & Nep Cai Hoa Vang & 135.25 & 71.17 & 94.50 & 30.42 & 71.25 \\
\hline 6 & Nep Thuy Tien & 126.08 & 66.08 & 89.75 & 29.75 & 71.35 \\
\hline 7 & IR64 & 340.83 & 184.33 & 334.75 & 178.25 & 80.10 \\
\hline 8 & Ai32 & 419.50 & 166.08 & 497.00 & 243.58 & 73.35 \\
\hline 9 & $\mathrm{X} 21$ & 350.42 & 177.92 & 369.00 & 196.50 & 73.55 \\
\hline 10 & Q5 & 355.92 & 150.92 & 444.50 & 239.50 & 72.05 \\
\hline 11 & $\mathrm{C} 70$ & 509.25 & 199.33 & 562.33 & 252.42 & 73.60 \\
\hline 12 & Khang Dan & 401.83 & 150.17 & 492.75 & 241.08 & 73.10 \\
\hline 13 & $\mathrm{XI} 23$ & 356.50 & 175.25 & 367.58 & 186.33 & 72.30 \\
\hline 14 & $108 \mathrm{AV}$ & 406.50 & 172.67 & 484.50 & 250.67 & 74.15 \\
\hline 15 & IR352 & 216.83 & 126.42 & 141.92 & 51.50 & 73.00 \\
\hline 16 & Koshihikari & 364.17 & 207.33 & 262.58 & 105.75 & 73.00 \\
\hline 17 & Hiyokumochi & 72.83 & 41.25 & 46.75 & 15.17 & 70.75 \\
\hline 18 & Hoshinishiki & 255.00 & 123.75 & 285.75 & 154.50 & 70.65 \\
\hline 19 & Nipponbare & 320.50 & 187.25 & 242.92 & 109.67 & 73.00 \\
\hline 20 & Milkyqueen & 375.00 & 249.75 & 199.75 & 74.50 & 73.40 \\
\hline
\end{tabular}


be much higher than that of Vietnamese rice.

\section{Instrumental and chemical measurement correlation}

Whiteness and difference in color of milled rice The whiteness of rice positively correlates with the degree of milling. It is also influenced by the inherent characteristics of certain rice vari- eties. Glutinous rice is whiter than non-glutinous rice (Juliano et al., 1981). Since the Vietnamese rice, Nep cai hoa vang is a glutinous rice and is characterized by its opacity, its whiteness reading was the highest (56.8, Table 7). On average, Japanese rice is whiter than Vietnamese rice (40.42 compared to 36.9).

Table 7. Properties of samples using instrumental tests.

\begin{tabular}{|c|c|c|c|c|c|c|c|c|c|c|}
\hline \multirow{2}{*}{ No } & \multirow{2}{*}{ Sample } & \multirow{2}{*}{ Mido score } & \multirow{2}{*}{ Glossiness } & \multirow{2}{*}{ Whiteness } & \multicolumn{3}{|c|}{ Color } & \multicolumn{3}{|c|}{ Rice analyzer } \\
\hline & & & & & $L$ & $a$ & $b$ & Moisture (\%) & Amylose $(\%)$ & Protein $(\%)$ \\
\hline 1 & $\mathrm{P} 4$ & 56.8 & 3.2 & 37.3 & 72.5 & 0.84 & 16.1 & 12.9 & 15.4 & 9.0 \\
\hline 2 & Tam Ap Be & 51.2 & 3.6 & 37.2 & 74.2 & 0.49 & 18.9 & 12.8 & 15.6 & 9.4 \\
\hline 3 & Bac Huong & 62.1 & 4.0 & 32.1 & 70.7 & 1.00 & 18.6 & 14.6 & 18.1 & 8.9 \\
\hline 4 & Tam Xoan & 46.2 & 3.5 & 34.5 & 72.4 & 0.69 & 19.1 & 13.9 & 17.3 & 9.4 \\
\hline 5 & Nep Cai Hoa Vang & 63.5 & 4.4 & 56.8 & 85.2 & -0.35 & 14.0 & 8.0 & 12.0 & 4.0 \\
\hline 6 & Nep Thuy Tien & 62.8 & 4.1 & 54.1 & 83.6 & -0.28 & 14.4 & 8.0 & 12.0 & 4.0 \\
\hline 7 & IR64 & 40.6 & 3.0 & 33.2 & 71.1 & 1.25 & 17.5 & 13.0 & 16.3 & 10.3 \\
\hline 8 & Ai32 & 49.4 & 3.6 & 39.4 & 74.9 & 0.40 & 17.0 & 13.0 & 16.3 & 6.5 \\
\hline 9 & $\mathrm{X} 21$ & 62.8 & 3.2 & 33.9 & 71.3 & 1.34 & 16.4 & 12.8 & 17.0 & 7.9 \\
\hline 10 & Q5 & 55.1 & 3.1 & 36.3 & 73.0 & 1.15 & 16.8 & 13.4 & 16.9 & 6.9 \\
\hline 11 & $\mathrm{C} 70$ & 45.6 & 4.8 & 41.8 & 76.6 & -0.17 & 16.6 & 13.3 & 17.6 & 7.6 \\
\hline 12 & Khang Dan & 50.6 & 3.1 & 35.0 & 72.5 & 1.12 & 17.0 & 13.1 & 16.9 & 7.1 \\
\hline 13 & $\mathrm{XI} 23$ & 63.2 & 3.5 & 33.6 & 71.3 & 1.01 & 16.6 & 13.0 & 17.2 & 8.8 \\
\hline 14 & $108 \mathrm{AV}$ & 59.3 & 4.1 & 36.0 & 72.7 & 0.75 & 16.9 & 13.6 & 17.4 & 7.6 \\
\hline 15 & IR352 & 55.7 & 3.9 & 48.5 & 81.7 & 0.42 & 15.1 & 8.0 & 12.0 & 4.0 \\
\hline 16 & Koshihikari & 68.8 & 5.6 & 37.9 & 74.8 & 0.24 & 17.7 & 14.3 & 16.5 & 6.2 \\
\hline 17 & Hiyokumochi & 56.2 & 4.1 & 49.2 & 82.9 & 0.15 & 15.1 & 8.0 & 12.0 & 4.0 \\
\hline 18 & Hoshinishiki & 64.4 & 6.3 & 38.4 & 75.6 & 0.07 & 18.8 & 14.3 & 17.8 & 7.1 \\
\hline 19 & Nipponbare & 63.0 & 6.4 & 36.3 & 74.2 & 0.20 & 18.6 & 14.1 & 17.4 & 8.3 \\
\hline 20 & Milkyqueen & 64.1 & 5.7 & 40.3 & 77.8 & 0.13 & 18.8 & 14.0 & 17.0 & 7.3 \\
\hline
\end{tabular}

(a)

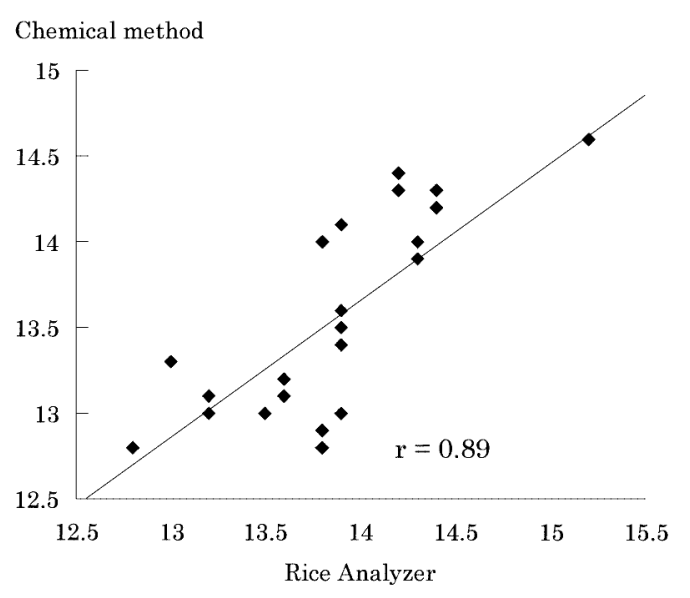

(b)

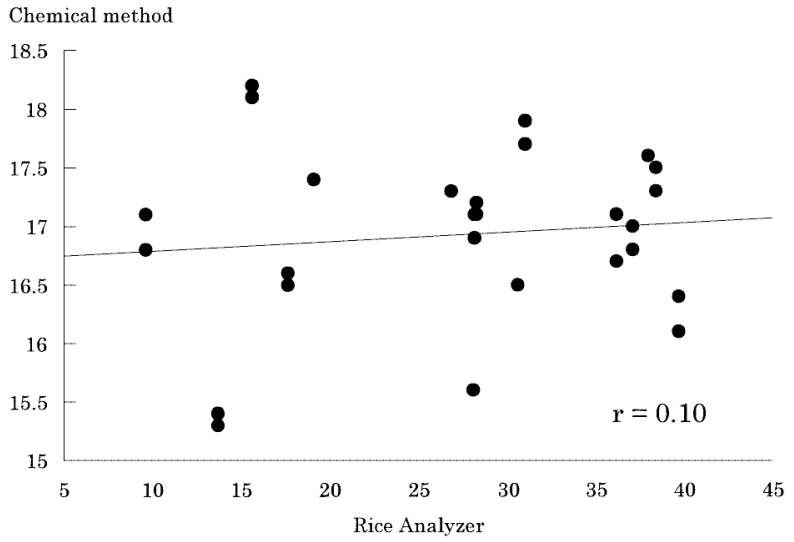

(c)

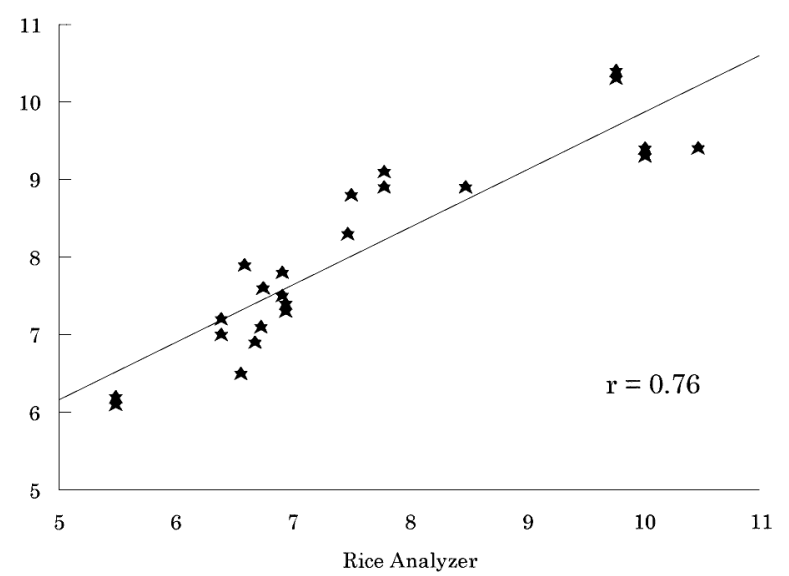

Fig. 1. Correlation between Rice Analyzer and Chemical method in measurement of main chemical components. (a) moisture content, (b) amylose content, (c) protein content. 
As when a whiteness meter is used, a difference color meter showed that glutinous rice tended to be lighter than non-glutinous rice. Nep cai hoa vang was also lightest with a value of 85.2. Vietnamese is higher than Japanese rice in red color value on average (0.64 compared to 0.16$)$ but is lower in yellow value (16.73 compared to 17.8).

Glossiness As seen in Table 7, the glossiness of Japanese rice after cooking is higher than Vietnamese rice, although Japanese glutinous rice had glossiness values lower than non-glutinous rice.

Taste score (Mido score) Satake Co., Ltd., developed a "taste analyzer" in the 1980s which combined the concept of an estimation formula of eating quality based on physicochemical measurements and the NIR (near infrared spectroscopy) technique. The principle of the taste analyzer is based on the multiple regression analysis using NIR data (protein, moisture, amylose and fat acidity) against the results of sensory test. Yamagata of the Japan Association of Milling Companies tested 3 different eating quality evaluation systems by NIR and reported that the "Mido score," a kind of taste score, correlated significantly with the results of sensory test $(r=0.54-0.63)$, although the scores were affected by the moisture contents and milling yield (Yamagata et al., 1990). There are 8 companies in Japan which have developed characteristic systems to evaluate the eating quality of rice grains based on a spectroscopic technique. More than 1000 agricultural cooperatives, wholesalers and retailers introduced these NIR systems to evaluate the qualities of their grains. The Food Agency of Japan carried out a survey in 1996 on the eating quality evaluation systems. According to their report, about $67 \%$ of users were satisfied with the performance of the system. The data on protein and moisture are very reliable but some users request improved accuracy in the Mido score and amylose. Recently, several many Japanese companies, Satake, Toyo, Shimadzu and others, have developed a taste-meter to measure rice taste. In this study, we used the Toyo Mido Meter, a product of Toyo Seimaiki Seisaksho Co., Ltd. The Mido scores are shown in Table 7. Most scores of Japanese rice were higher than the Vietnamese. These taste-meters, however, were produced to measure Japanese rice with low amylose and protein content only. They are not suitable to measure Vietnamese rice which ranges widely in amylose and protein content; further, Vietnamese rice does not meet the requirements of the Japanese standard for quality. The Japanese rice, Koshihikari gave the highest mido score (68.8, Table 7) as the favorite rice in Japan.

Using a rice analyzer for measuring the main chemical components of rice is a nondestructive evaluation method. It is more rapid and we can save on the amount of samples (Table 6). We obtained the same results in measuring all parameters of Japanese and Vietnamese glutinous rice (moisture, amylose, and protein content). There was a highly significant correlation between the chemical method and rice analyzer in measuring moisture and protein content of non-glutinous rice, $r=0.89$ and 0.76 , respectively (Fig.1). However, for amylose content measurement, the correlation was weak and was nearly zero $(r=0.1)$. The Shimadzu rice analyzer RQ1-Plus is considered the only one suitable for measuring non-glutinous rice and moisture and protein content. Shimizu et al. $(1999,2001)$ recently developed a suitable calibration for amylose measurement and the pasting measurement of Japanese rice with narrow range and low amylose content. Development of a means of calibration for the physical properties of rice grains, such as stickiness and hardness of cooked rice, is another task for near-infrared spectroscopy researchers in the future.

Acknowledgment The present authors express deep gratitude that a part of this research was supported by the fund of BRAIN (Bio-oriented Technology Research Advancement Institution). We express our gratitude to Prof. Dr. Le Doan Dien (Post Harvest Institute, Hanoi, Vietnam) for his provision of Vietnamese rice samples.

\section{References}

Batcher, O.M., Helmintoller, K.F. and Dawson. E.H. (1956). Rice J., 59, 4-8.

IRPS. (1982). An international survey of methods used for evaluation of the cooking and eating qualities of milled rice No 77

Duncombe, W.G. (1963) Biochem J., 88, 7.

Juliano, B.O. and Villareal, C.P. (1993). Grain quality evaluation of world rices. International Rice Research Institute, Manila, Philippines, $205 \mathrm{p}$.

Juliano, B.O. (1971). A simplified assay for milled-rice amylose. Cereal Sci. Today., 12, 334-360.

Juliano, B.O. (1981). Physical and mechanical properties of rice. Rice Chemistry and Technology. AACC, USA, pp. 207-231

Ohtsubo, K. (1995). Quality Control. Rice Post-harvest Technology. The Food Agency, MAFF, Japan.

Ohtsubo, K., Kobayashi, A., and Shimizu, H. (1993). Quality evaluation of rice in Japan. J. Agric. Res. Q., 27, 95-101.

Ohtsubo, K., Toyoshima, H. and Okadome, H. (1998). Quality assay of rice using traditional and novel tools. Cereal Food World., 43, 203-206.

Ohtsubo, K., Yanase, H. and Ishima, T. (1987). Colorimetric determination of fat acidity in rice-Relation between quality change of rice during storage and fat acidity determined by improved Duncombe method. Rep. Natl. Food Res. Inst., 51, 59-65.

Okabe, M. (1979). Texture measurements of cooked rice and its relationship to the eating quality. J. Texture Stud., 10, 131-152.

Okadome, H., Toyoshima, H. and Ohtsubo, K. (1996). Many-sided evaluation of physical properties of cooked rice grains with a single apparatus. J. Jpn. Soc. Food. Sci. Technol., 43, 1004-1011.

Okadome, H., Toyoshima, H. and Ohtsubo, K. (1999). Multiple measurements of physical properties of individual cooked rice grains with a Single Apparatus. Cereal Chem., 76, 855-860.

Okadome, H., Toyoshima, H., Shimizu, N., Akinaga, T. and Ohtsubo, K. (2001). Chemometric formulas based on physical properties of single cooked milled rice grains for determination of amylose and protein contents. J. Food Sci., In press.

Ross, A.S., Walker, C.E, Booth, R.I., Orth, R.A. and Wringlay, C.W. (1987). The RVA: A new technique for the estimation of sprout damage. Cereal Foods World., 32, 827-829.

Shimizu, N., Katsura, J., Yanagisawa, T., Inoue, S., Withey, R.P., Cowe, I.A., Eddison, C.G., Blankeley, A.B., Kimura, T., Yoshizaki, S., Okadome, H., Toyoshima, H. and Ohtsubo, K. (1999). Determination of apparent amylose content in Japanese milled rice using near-infrared transmittance spectroscopy. Food Sci. Technol. Res., 5, $337-342$.

Shimizu, N., Yanagisawa, T., Okadome, H., Toyoshima, H., Andren, H., Kimura, T. and Ohtsubo, K. (2001). Determination of maximum viscosity of milled rice flours using near-infrared transmittance spectroscopy. Food Sci. Technol. Res., 7, 104-109.

Taira, H. (1985). Paddy and Rice. Bio-oriented industrial technology research advancement institution, 103-129.

Toyoshima, H., Okadome, H., Ohtsubo, K., Suto, M., Horisue, N., Inatsu, O., Narizuka, A., Aizaki, M., Inouchi, N. and Fuwa, H. (1997). Cooperative test on the small-scale rapid method for the gelatinization properties test of rice flours with a RVA. Nippon Shokuhin Kagagu Kogakukaishi, 44, 579-584 (in Japanese).

Villareal, C.P., De la Druz, N.M. and Juliano, B.O. (1994). Rice amylose analysis by near-infrared transmittance spectroscopy. Cereal Chem., 71, 292-296.

Walker, C.E., Ross, A.S., Wrigley, C.W. and McMaster, G.J. (1988). Accelerated characteristics of starch past viscosity and set-back with the RVA. Cereal Foods World, 33, 491-494.

Yamagata, I., Andoh, M. and Yanase, H. (1990). Characteristics of eating quality evaluation system. Seimai Kogyo, 123, 10-20 (in Japanese). 